\title{
Faecal elastase 1: not helpful in diagnosing chronic pancreatitis associated with mild to moderate exocrine pancreatic insufficiency
}

\author{
P G Lankisch, I Schmidt, H König, D Lehnick, R Knollmann, M Löhr, S Liebe
}

\begin{abstract}
BackgroundlAim-The suggestion that estimation of faecal elastase 1 is a valuable new tubeless pancreatic function test was evaluated by comparing it with faecal chymotrypsin estimation in patients categorised according to grades of exocrine pancreatic insufficiency (EPI) based on the gold standard tests, the secretinpancreozymin test (SPT) and faecal fat analysis.
\end{abstract}

Methods-In 64 patients in whom EPI was suspected, the following tests were performed: SPT, faecal fat analysis, faecal chymotrypsin estimation, faecal elastase 1 estimation. EPI was graded according to the results of the SPT and faecal fat analysis as absent, mild, moderate, or severe. The upper limit of normal for faecal elastase 1 was taken as $200 \mu \mathrm{g} / \mathrm{g}$, and for faecal chymotrypsin $3 \mathrm{U} / \mathrm{g}$ stool. Levels between 3 and $6 \mathrm{U} / g$ stool for faecal chymotrypsin are usually considered to be suspicious for EPI. In this study, both 3 and $6 \mathrm{U} / \mathrm{g}$ stool were evaluated as the upper limit of normal.

Results-Exocrine pancreatic function was normal in 34 patients, of whom 94, 91, and $79 \%$ had normal faecal elastase 1 and faecal chymotrypsin levels $(<3 \mathrm{U} / \mathrm{g}$ and $<6$ U/g) respectively. Thirty patients had EPI, of whom 53, 37, and 57\% had abnormal faecal enzyme levels (differences not significant). When EPI was graded as mild, moderate, or severe, $63 \%$ of patients had mild to moderate EPI, and $37 \%$ had severe EPI. In the latter group, between 73 and $91 \%$ of patients had abnormal faecal enzymes. In the group with mild to moderate EPI, abnormal test results were obtained for both faecal enzymes in less than $50 \%$ of the patients (differences not significant). Some $40 \%$ of the patients had pancreatic calcifications. There were no significant differences for either faecal enzyme between the two groups with and without pancreatic calcifications. In $62 \%$ of the patients who underwent an endoscopic retrograde cholangiopancreatography (ERCP), abnormal duct changes were found. Again, there were no significant differences for either faecal enzyme between the two groups with abnormal and normal ERCP.

Conclusion-Estimation of faecal elastase 1 is not distinctly superior to the traditional faecal chymotrypsin estima- tion. The former is particularly helpful only in detecting severe EPI, but not the mild to moderate form, which poses the more frequent and difficult clinical problem and does not correlate significantly with the severe morphological changes seen in chronic pancreatitis.

(Gut 1998;42:551-554)

Keywords: faecal elastase 1 ; faecal chymotrypsin; secretin-pancreozymin test; faecal fat analysis; exocrine pancreatic insufficiency; diagnosis

The diagnosis of chronic pancreatitis is usually based on abnormal results from pancreatic function tests and morphological examination. ${ }^{1}$ For the evaluation of exocrine pancreatic function, there are both direct and indirect tests. The gold standard is the secretinpancreozymin test (SPT) or one of its modifications. However, these can only be carried out at qualified gastroenterological centres since the test is time consuming, invasive, and expensive. $^{23}$ Therefore a number of indirect tests of pancreatic function that measure pancreatic enzymes in serum, such as pancreatic isoamylase and immunoreactive trypsin, or split products in serum or urine, such as the NBT-PABA test or the pancreolauryl test, or faecal contents of enzymes, such as chymotrypsin, have been developed and evaluated for diagnosing exocrine pancreatic insufficiency (EPI). None has become an accepted gold standard for doctors in clinical practice outside of gastroenterological centres. Therefore the isolation of pancreatic elastase 1 and its further characterisation as a human- and pancreasspecific enzyme that is not degraded during intestinal transport and that is enriched 5- to 6-fold in faeces compared with duodenal juice is of interest. ${ }^{4-6} \mathrm{~A}$ highly sensitive enzyme linked immunosorbent assay (ELISA) for human faecal and duodenal elastase 1 using two specific monoclonal antibodies is commercially available. ${ }^{4-6}$ Preliminary studies ${ }^{7-10}$ seem to indicate that faecal elastase 1 estimation is a valuable test of pancreatic function and could become a new gold standard indirect test of pancreatic function. ${ }^{11}$ The aim of our study was to evaluate faecal elastase 1 estimations in patients categorised according to grades of EPI based on the gold standard tests, SPT and faecal fat analysis. Furthermore, we aimed to find out whether this new test is really better than the traditionally used estimation of faecal chymotrypsin. 
Table 1 Estimation of faecal elastase 1 and faecal chymotrypsin in patients with exocrine pancreatic insufficiency of varying severity

\begin{tabular}{|c|c|c|c|c|}
\hline & \multirow[b]{2}{*}{ Number } & \multirow[b]{2}{*}{$\begin{array}{l}\text { Abnormal faecal elastase } \\
1(<200 \mu \mathrm{g} / \mathrm{g} \text { stool })\end{array}$} & \multicolumn{2}{|c|}{ Abnormal faecal chymotrypsin } \\
\hline & & & $<3 \mathrm{U} / \mathrm{g}$ stool & $<6 \mathrm{U} / \mathrm{g}$ stool \\
\hline \multicolumn{5}{|c|}{ Exocrine pancreatic insufficiency } \\
\hline Absent & 34 & $2(6)$ & $3(9)$ & $7(21)^{\star}$ \\
\hline Present & 30 & $16(53)$ & $11(37)$ & $17(57) \dagger$ \\
\hline Mild & 10 & $4(40)$ & $1(10)$ & $3(30) \ddagger$ \\
\hline Moderate & 9 & $3(33)$ & $2(22)$ & $4(44) \S$ \\
\hline Severe & 11 & $9(82)$ & $8(73)$ & $10(91) \uparrow$ \\
\hline
\end{tabular}

Values in parentheses are percentages.

Faecal elastase $1 v$ faecal chymotrypsin $<3 \mathrm{U} / \mathrm{g}$ stool and $<6 \mathrm{U} / \mathrm{g}$ stool (McNemar test): ${ }^{\star} \mathrm{p}=1$, $\mathrm{p}=0.18, \mathrm{NS} ; \mathrm{tp}=0.13, \mathrm{p}=1$, NS; $\neq \mathrm{p}=0.25, \mathrm{p}=1, \mathrm{NS} ; \mathrm{p}=1, \mathrm{p}=1, \mathrm{NS} ; \mathrm{q}=1, \mathrm{p}=1, \mathrm{NS}$.

Table 2 Estimation of faecal elastase 1 and faecal chymotrypsin in patients with compensated (no steatorrhoea) and decompensated (steatorrhoea) exocrine pancreatic insufficiency

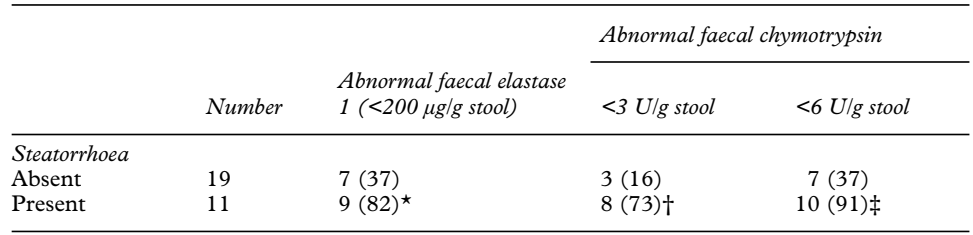

Values in parentheses are percentages.

${ }^{\star} \mathrm{p}=0.03, \mathrm{tp}=0.004, \neq \mathrm{p}=0.03$.

\section{Methods}

Exocrine pancreatic function was tested in 64 patients sent to our department within 24 months with suspected EPI by means of SPT, ${ }^{12}{ }^{13}$ quantitative faecal fat analysis, ${ }^{14}$ and faecal chymotrypsin (Boehringer-Mannheim, Mannheim, Germany) and elastase 1 (ScheboTech, D-35435 Wettenberg, Germany) estimations. The latter three tests were performed on three stool samples collected over 24 hours for three days, and mean values were determined. Normal values were: (a) SPT: after secretin administration, fluid secretion $>67 \mathrm{ml} / 30 \mathrm{~min}$, bicarbonate concentration $>70 \mathrm{mmol} / \mathrm{l}$, bicarbonate output $>6.5 \mathrm{mmol} / 30 \mathrm{~min}$; after cholecystokinin-pancreozymin administration, amylase output $>12000 \mathrm{U} / 30 \mathrm{~min}$, lipase output $>65000 \mathrm{U} / 30 \mathrm{~min}$, and trypsin output $>30$ $\mathrm{U} / 30 \mathrm{~min}$; (b) faecal fat $<7 \mathrm{~g} /$ day; (c) faecal elastase $1>200 \mu \mathrm{g} / \mathrm{g}$ stool; (d) faecal chymotrypsin $<3 \mathrm{U} / \mathrm{g}$ stool. Since values between 3 and $6 \mathrm{U} / \mathrm{g}$ are indicative of EPI, both measurements - that is, 3 and $6 \mathrm{U} / \mathrm{g}$ stoolwere taken as the upper limit of normal. Exocrine pancreatic function was evaluated as normal or abnormal according to the result of the SPT. In the case of an abnormal test result, EPI was classified as mild (reduced output of

Table 3 Estimation of faecal elastase 1 and faecal chymotrypsin in patients with exocrine pancreatic insufficiency and morphological changes in the pancreas indicative of chronic pancreatitis

\begin{tabular}{|c|c|c|c|c|}
\hline & \multirow[b]{2}{*}{ Number } & \multirow[b]{2}{*}{$\begin{array}{l}\text { Abnormal faecal elastase } \\
1(<200 \mu \mathrm{g} / \mathrm{g} \text { stool })\end{array}$} & \multicolumn{2}{|c|}{ Abnormal faecal chymotrypsin } \\
\hline & & & $<3 \mathrm{U} / \mathrm{g}$ stool & $<6 \mathrm{U} / \mathrm{g}$ stool \\
\hline \multicolumn{5}{|c|}{ Morphological changes } \\
\hline \multicolumn{5}{|c|}{ Calcifications } \\
\hline Absent & 18 & $9(50)$ & $4(22)$ & $10(56)$ \\
\hline Present & 12 & $7(58)^{\star}$ & $7(58) \dagger$ & $7(58) \ddagger$ \\
\hline \multicolumn{5}{|l|}{ ERCP } \\
\hline Normal & 5 & $2(40)$ & $2(40)$ & $3(60)$ \\
\hline Abnormal & 8 & $7(88) \S$ & $6(75) \rrbracket$ & $6(75)^{\star \star}$ \\
\hline
\end{tabular}

Values in parentheses are percentages.

Fisher's exact test: ${ }^{\star} \mathrm{p}=0.72,+\mathrm{p}=0.06, \neq \mathrm{p}=1, \S \mathrm{p}=0.22, \uparrow \mathrm{p}=0.29,{ }^{\star \star} \mathrm{p}=1$. one or more enzymes; bicarbonate concentration and faecal fat excretion normal), moderate (reduced enzyme output and bicarbonate concentration; faecal fat excretion normal) or severe (reduced enzyme output and bicarbonate concentration plus steatorrhoea). ${ }^{313}$ For morphological evaluation of the pancreas, a plain abdominal $x$ ray of the pancreatic area or an ultrasound examination of the pancreas was performed to detect pancreatic calcifications in patients with EPI. In addition, an endoscopic retrograde cholangiopancreatography (ERCP) was performed when indicated; the results were expressed in terms of the Cambridge classification. ${ }^{15} 16$ For statistical evaluation of the test results, sensitivity and specificity rates as well as the McNemar and the Fisher's exact tests were used.

\section{Results}

Faecal elastase 1 was abnormal in two $(6 \%)$ of 34 patients with non-pancreatic disease and a normal SPT, and faecal chymotrypsin was abnormal in three $(9 \%)$ and seven $(21 \%)$ of these patients, taking 3 and $6 \mathrm{U} / \mathrm{g}$ stool respectively as the upper limit of normal. Thus the specificity of the elastase 1 determination was $94 \%$, and that for chymotrypsin 91 and $79 \%$, depending on the upper limit of normalcy (table 1; McNemar test: $\mathrm{p}=1$ and $\mathrm{p}=0.18$, differences not significant). Faecal elastase 1 was abnormal in $16(53 \%)$ and faecal chymotrypsin in $11(37 \%)$ and $17(57 \%)$ of 30 patients with EPI (McNemar test: $p=0.13$ and $\mathrm{p}=1$, not significant; table 1 ). When patients were graded into groups of different degrees of EPI, 10 had mild, 9 moderate, and 11 severe insufficiency. In the severe group, the percentages of abnormal test results were high, with $82 \%$ abnormal results for elastase 1 and 73 and $91 \%$ for chymotrypsin estimations for the two lower limits of normal. However, in the groups with mild and moderate EPI, abnormal test results were observed in less than $50 \%$ of the patients (table 1; differences not significant for any stage; McNemar test, faecal elastase $1 v$ faecal chymotrypsin $<3 \mathrm{U} / \mathrm{g}, \mathrm{p}=0.25, \mathrm{p}=1$ and $\mathrm{p}=1$, and $<6 \mathrm{U} / \mathrm{g}, \mathrm{p}=1, \mathrm{p}=1, \mathrm{p}=1$ ). When patients were divided into two groups according to the presence or absence of steatorrhoea as an indication of pancreatic enzyme substitution, 11 (37\%) had steatorrhoea and $19(63 \%)$ none (table 2). The first group, as already shown in table 1 , had a high percentage of abnormal test results, with $82 \%$ for faecal elastase 1 and 73 and $91 \%$ for faecal chymotrypsin. This was significantly better than the group without steatorrhoea where only 37,16 and $37 \%$ had abnormal estimations (table 2; Fisher's exact test, $\mathrm{p}=0.03,0.004$, and 0.03, all significant). Finally, faecal test results were compared with the absence or presence of morphological changes in the pancreas - that is, calcifications of the organ or duct changes as shown on plain abdominal $x$ ray and ERCP. In $12(40 \%)$ of the 30 patients, calcifications were found (table 3). Abnormal faecal enzyme estimations were found in 58\% or less of the patients. There were no significant differences for faecal elastase 1 and faecal chy- 
motrypsin ( $<3$ and $<6 \mathrm{U} / \mathrm{g}$ stool) between patients with or without calcifications (Fisher's exact test, $\mathrm{p}=0.72,0.06$, and 1.0). An ERCP was performed for diagnostic purposes in 13 patients. Five $(38 \%)$ had a normal, and eight $(62 \%)$ an abnormal duct system (table 3 ). There were no significant differences for elastase 1 and chymotrypsin test estimations ( $<3$ and $<6 \mathrm{U} / \mathrm{g}$ stool) between patients with normal and abnormal ERCP (Fisher's exact test, $\mathrm{p}=0.22,0.29$, and 1.0 respectively).

\section{Discussion}

Only four full research studies have been published on the value of faecal elastase 1 measures in the diagnosis of EPI induced by chronic pancreatitis. ${ }^{17-20}$ They differ considerably in diagnostic criteria for chronic pancreatitis, the diagnostic gold standard with which faecal enzyme estimation was compared, the grade of severity of either pancreatic function or chronic pancreatitis, and, last but not least, the number of patients investigated. Domínguez-Muñoz et $a l^{17}$ investigated 36 patients with nonpancreatic diseases and 20 with chronic pancreatitis, diagnosed and graded into mild (n $=6)$ and moderate/severe $(n=14)$. Specificity was $83 \%$ for elastase 1 estimation and $92 \%$ for chymotrypsin estimation. Sensitivity was zero for both enzymes in mild chronic pancreatitis, and $100 \%$ and $57 \%$ for elastase 1 and chymotrypsin respectively in the moderate/severe group. They concluded that determination of faecal elastase 1 is a simple and accurate test of chronic pancreatitis, with the same specificity as chymotrypsin estimation and a higher sensitivity than the other faecal enzyme estimations. Amann $e t a l^{18}$ diagnosed chronic pancreatitis by one or more of the following criteria: an abnormal SPT, radiographic evidence of pancreatic calcifications, case history of pancreatic surgery for complications of chronic pancreatitis, and an abnormal ERCP. On the basis of these criteria plus clinical evidence or tests of malabsorption, they divided a group of 14 patients with chronic pancreatitis into those with mild/ moderate and severe disease, with seven patients in each group. Sensitivity was $43 \%$ in the first and $100 \%$ in the second group. Specificity of the test was $29 \%$ in seven patients with non-pancreatic disorders leading to malabsorption. Stein $e t a l^{19}$ investigated 29 patients with chronic pancreatitis, in whom the diagnosis was made by SPT plus faecal fat analysis and other generally accepted criteria. On the basis of our staging systems, ${ }^{313}$ none of these patients had mild, seven had moderate and 22 severe EPI. Sensitivity for faecal elastase 1 and chymotrypsin estimation was 88 and $56 \%$ in the first, and 96 and $91 \%$ in the second group. The specificity of the two tests was 94 and $91 \%$ respectively. The cut-off value for elastase 1 used in this study was $175 \mu \mathrm{g} / \mathrm{g}$ wet weight stool, whereas all other studies used $<200 \mu \mathrm{g} / \mathrm{g}$ stool as the lower limit of normal. Recently, Löser $e t a l^{20}$ reported a study of 35 patients with non-pancreatic disease and 44 patients with EPI due to chronic pancreatitis. For the latter group, they used our staging system with the modification that bicarbonate concentration was replaced by bicarbonate output. Eight patients had mild, 14 moderate, and 22 severe EPI. Thus the two groups with compensated and non-compensated EPI amounted to 50\% of the cases. Abnormal faecal elastase 1 measures were found in 67,100 and $100 \%$ of these patients (overall sensitivity 93\%), whereas abnormal chymotrypsin measures were obtained for 63,79 , and $95 \%$ of patients (overall sensitivity $84 \%$ ). In our study, we found in accordance with the other four studies that assay of faecal elastase 1 is a good test for severe EPI. However, this is not the real diagnostic problem. Good overall results for this group of patients have been shown previously by our group using the NBT-PABA and pancreolauryl tests, both in serum and urine, ${ }^{1321}$ and severe steatorrhoea ( $>15 \mathrm{~g} /$ day) can even be diagnosed visually. ${ }^{22}$ The more frequent and difficult problem is how to diagnose mild to moderate EPI. In this group of patients, results from all investigators differ. DomínguezMuñoz et $a l^{17}$ and Amann et $a l^{18}$ have shown disappointing results for this group. In both studies, a comparison was made with results of morphological examinations, such as from ERCP, computed tomography, and $x$ ray investigations of the area of the pancreas. In the first study, the diagnosis of chronic pancreatitis was based solely on morphological investigations, such as ERCP and computed tomography, whereas in the second group, a number of pancreatic function tests and morphological examinations were used to make the diagnosis. To evaluate a pancreatic function test, comparison with another function test, in this case SPT, the gold standard, seems fair and appropriate. Stein et $a l^{19}$ have done so, but they only investigated a small group of patients with moderate EPI and none with the mild form, and their results may not be representative for both groups. The only study comparable with ours is the investigation of Löser et al. ${ }^{20}$ Their results differ considerably from ours. The sensitivity rate for elastase 1 estimation in patients with mild to moderate EPI is distinctly different, and so are the conclusions. Löser et $a l^{20}$ concluded that the sensitivity of elastase 1 estimation is excellent for moderate and severe EPI, but is limited for the mild disease. However, from our results we conclude that measuring faecal elastase 1 is only helpful for detecting severe EPI, and not the mild to moderate forms. Furthermore, the results do not correlate significantly with severe morphological changes as shown in chronic pancreatitis. There is no ready explanation for the differences between the two studies. The higher percentage of patients with mild to moderate EPI, $63 \%$ in our study compared with $50 \%$ in the study of Löser et $a l,{ }^{20}$ and the possible difference in origin of patients (most patients from a secondary primary referral centre in Lüneburg compared with a tertiary referral centre in Kiel) may have played a role. A decisive point may be the modification of our staging system ${ }^{3}{ }^{13}$ using bicarbonate output rather than bicarbonate concentration. In our experience, about a quarter of patients with abnormal bicarbonate concentration still have 
a normal bicarbonate output. Thus, in the group of patients with mild EPI in the study of Löser $e t a l,{ }^{20}$ there may have been some patients with abnormal bicarbonate concentration but normal bicarbonate output, who would have belonged to the moderate group according to our system. This would probably lower the sensitivity of the faecal elastase 1 estimation in the moderate group of Löser et al. ${ }^{20}$ Furthermore, in our view, faecal elastase 1 estimation was not superior to the traditionally used faecal chymotrypsin estimation. There were no significant differences between the two faecal enzyme estimations using 3 and $6 \mathrm{U} / \mathrm{g}$ chymotrypsin as the lower limit of normal. Finally, at a time of financial restriction, it should be taken into account that faecal elastase 1 estimation costs more than twice as much as faecal chymotrypsin estimation (23 $v 10 \mathrm{DM}$ in December 1996). In conclusion, we confirm that determination of faecal elastase 1 is useful in the diagnosis of severe EPI, but we cannot unreservedly recommend its use as a screening test, as the overall sensitivity rate is not convincing and not superior to the cheaper chymotrypsin test. We have either to wait for more reports on larger numbers of patients with gold standard proven and graded EPI or for another faecal test. In the meantime, standard chymotrypsin and/or the pancreolauryl tests may be used where SPT plus faecal fat estimation is not possible or the patient cannot be sent to a centre of gastroenterology capable of performing these tests. ${ }^{3}$

1 Lankisch PG. Chronic pancreatitis. In: Haubrich WS, Schaffner F, Berk JE, eds. Bockus gastroenterology, vol 4, 5th ed. Philadelphia, London, Toronto: Saunders, 1995;2930-58.

2 Lankisch PG. Progress report: exocrine pancreatic function tests. Gut 1982;23:777-98.

3 Lankisch PG, Andrén-Sandberg A. Standards for the diagnosis of chronic pancreatitis and for the evaluation of treatment. Int $\mathcal{F}$ Pancreatol 1993;14:205-12.

4 Sziegoleit A, Krause E, Klör H-U, et al. Elastase 1 and chymotrypsin B in pancreatic juice and feces. Clin Biochem motrypsin B in
5 Sziegoleit A, Linder D. Studies on the sterol-binding capacity of human pancreatic elastase 1. Gastroenterology 1991;100:768-74

6 Scheefers-Borchel U, Scheefers H, Arnold R, Fischer P, Sziegoleit A. Pankreatische Elastase 1: Parameter für die chronische und akute Pankreatitis. Lab Med 1992;16:42732.

7 Katschinski M, Schirra J, Bross A, et al. Fecal concentration of pancreatic elastase-1 accurately indicates exocrine pancreatic insufficiency [abstract]. Gastroenterology 1994; 106:A300.

8 Löser C, Mölgaard A, Fölsch UR. Elastase 1 in faeces: a novel highly sensitive and specific pancreatic function test for easy and inexpensive routine application [abstract]. Digestion 1995;56:301.

9 Stein J, Jung M, Zeuzem S, et al. Fecal elastase-1: a new tubeless test in the diagnosis of pancreatic insufficiency [abstract]. Gastroenterology 1994;106:A325.

10 Domínguez-Muñoz JE, Malfertheiner P, Hieronymus C, Sauerbruch T. Human elastase concentration in faeces: a simple and accurate pancreatic function test [abstract]. Gastroenterology 1994;106:A290.

11 Amann ST, Bishop M, Toskes PP. Fecal pancreatic elastase 1 : is it the test we have been looking for [abstract]? Gastroenterology 1995;108:A341.

12 Creutzfeldt W. Funktionsdiagnostik bei Erkrankungen des exokrinen Pankreas. Verhandlungen der Deutschen Gesellschaft für Innere Medizin 1964;70:781-801.

13 Lankisch PG, Schreiber A, Otto J. Pancreolauryl test. Evaluation of a tubeless pancreatic function test in comparison with other indirect and direct tests for exocrine pancreatic function. Dig Dis Sci 1983;28:490-3.

14 Van de Kamer JH, ten Bokkel Huinink H, Weyers HA. Rapid method for the determination of fat in feces. 7 Biol Chem 1949;177:347-55.

15 Sarner M, Cotton PB. Classification of pancreatitis. Gut 1984;25:756-9.

16 Sarner M, Cotton PB. Definitions of acute and chronic pancreatitis. Clin Gastroenterol 1984;13:865-70.

17 Domínguez-Muñoz JE, Hieronymus C, Sauerbruch T, Malfertheiner P. Fecal elastase test: evaluation of a new noninvasive pancreatic function test. Am f Gastroenterol 1995;90: 1834-7.

18 Amann ST, Bishop M, Curington C, Toskes PP. Fecal pancreatic elastase 1 is inaccurate in the diagnosis of chronic pancreatitis. Pancreas 1996;13:226-30.

19 Stein J, Jung M, Sziegoleit A, et al. Immunoreactive elastase I: clinical evaluation of a new noninvasive test of pancreatic function. Clin Chem 1996;42:222-6.

20 Löser C, Möllgaard A, Fölsch UR. Faecal elastase 1: a novel, highly sensitive, and specific tubeless pancreatic function test. Gut 1996;39:580-6.

21 Lankisch PG, Brauneis J, Otto J, Göke B. Pancreolauryl and NBT-PABA tests. Are serum tests more practicable alternatives to urine tests in the diagnosis of exocrine pancreatic insufficiency? Gastroenterology 1986;90:350-4.

22 Lankisch PG, Dröge M, Hofses S, et al. Steatorrhoea: you cannot trust your eyes when it comes to diagnosis. Lancet 1996;347:1620-1. 